\title{
Advantages and pitfalls of training in a Lebanese manufacturing Company: a qualitative approach
}

\author{
Antranig TANGOUKIAN, Jennifer ABOU HAMAD and Elie MENASSA \\ Notre Dame University, Louaize, Lebanon \\ Correspondence should be addressed to: Jennifer ABOU HAMAD; jabouhamad@ndu.edu.lb \\ Received date: 6 April 2015; Accepted date: 3 July 2015; Published date: 16 February 2016 \\ Copyright (C) 2016. Antranig TANGOUKIAN, Jennifer ABOU HAMAD and Elie MENASSA. Distributed under \\ Creative Commons CC-BY 4.0

\begin{abstract}
Not long ago, companies started investing millions of dollars on training and educating their workforce on new skills and improving prior skills. This increase in investment in training is mainly due to the rapid changes in technology and intense competition in the open market. However, this investment varied from one company to another. Training is a tool and a way to acquire new and different set of knowledge, skills and attitudes that are work related, and can have short and long term benefits for the employee and the organization. Training and development is a new process in the Lebanese market. From the many positive effects and benefits of training on companies and organizations, working conditions and career development are considered the most vital, especially to manufacturing companies. The purpose of this article is to identify the benefits and the challenges of training. Hence, a qualitative exploratory approach is used. Managers from one of the leading Lebanese manufacturing company were interviewed to detect their perceptions about the effect of training on their employees and to determine on what basis the training is provided to employees.
\end{abstract}

Keywords: Training, Benefits, Challenges, Manufacturing Company.

Cite this Article as: Antranig TANGOUKIAN, Jennifer ABOU HAMAD and Elie MENASSA (2016), "Advantages and pitfalls of training in a Lebanese manufacturing Company: a qualitative approach" The MENA Journal of Business Case Studies, Vol. 2016 (2016), Article ID 866941, DOI: 10.5171/2016.866941 


\section{Introduction}

Training according to Sultana et al., (2012, p.467) "generates benefits for the employee as well as for the organization by positively influencing employee performance through the development of employee knowledge, skills, ability, competencies and behavior". That is training is a tool and a way to acquire new and different set of knowledge, skills and attitudes that are work related, and can have short and long term benefits for the employee and the organization.Companies have started investing millions of dollars on training and educating their workforce on new skills and how to improve prior skills. However, the amount of the investment varied from one country to another and even from one company to another Coget (2011). According to Robert and Shamsuddin (2000) companies that valued the implementation of training and development, witnessed a higher profitability and employee satisfaction, than companies with no or little training and human development focus.

Training and development is a new process in the Lebanese market, $\mathrm{HR}$ as a whole is a new concept field in Lebanon, since most companies are small to medium sized, and big companies are largely family oriented, with little training and development opportunities (Dirani, 2006). From the many positive effects and benefits of training on companies and organizations, working conditions and career development are considered the most vital, especially to manufacturing companies. Hence, when employees have a better awareness on safety and health issues and a perception on work actions, they are less prone to have work related accidents, better health, and as a result, less absenteeism, less turnover and increased job satisfaction (Cole 2002, cited in Nassazi 2013).

The purpose of this article is to identify the benefits and the challenges of training. Hence, a qualitative exploratory approach is used. Managers from a Lebanese manufacturing company were interviewed to detect their perceptions about the effect of training on their employees.

\section{Literature review}

In any organization the most important key to its success is the quality of the people employed in it, that is its' workforce. Hence, any organization seeking to gain growth and sustain in these current competitive market must improve the quality of its employees. One way for achieving this growth and success is through training. Training's importance can be clearly understood when an organization trains an employee and has a direct positive impact on the employee's performance and hence an improvement in the company's performance.

As mentioned by Beardwell and Holden (2001) cited in Nassazi (2013), "training is a learning experience which creates a permanent change in the skills, knowledge and attitude of individuals on a currently held job, and also enables employees to gain knowledge which they can transfer to other job areas".

Training throughout the last decade has seen a significant growth in importance and influence in different industries in the market. A major increase in its importance is mainly due to the intensification of competition between organizations in the open global market and also due to the rapid change in technology and processes. According to Milhem et al., (2014) organization's number of training hours dedicated to their workforce increased in average from 4,000 hours in 2009 to 4,540 hours in 2010. Consequently, organizations found out that investing in employee training plans has a major influence on an organizations' success, and as a result emphasized on training to gain competitive edge in the market and to keep their employees on the top of their job. Organizations are investing millions of dollars on training and educating their workforce on new skills. As statistics 
indicate, investments made by organizations on training are continuously growing.

However, many organizations set their training plans in an unplanned and unsystematic manner without identifying the training needs of the department or the organization, and as a result the trainings implemented will not be successful and might even have negative consequences. Hence, as investments in trainings continue to increase, organizations should clarify to their workforce the need for the training and its impact on the organization. As mentioned by Sultana (2012), the more a trainee is motivated, the quicker he or she will acquire a new skill. Moreover, Jolles (2005) states that stressing the significance of the training to employees would make them comprehend the need for that training; that is it should answer "what's in it for me?"

\section{Training Process}

For an organizational training to be effective it must follow a certain designed process and not just be view training as something that has to be done. Training should be viewed as an integrated process which transforms organizational inputs into organizational needed output (Blanchard and Thacker, 2006).

The training process begins with a triggering event. A triggering event occurs when a manager identifies the actual organizational performance is less than the expected organizational performance, this means that there is a gap somewhere. As a result, there should be some design to identify the gap, and deal with it accordingly to diminish or close the gap. One of the most successful methods used for transfer of learning and training by organizations is the ADDIE model. ADDIE is an instructional model defined by Gagne et al., (2005) (cited in Koohang and Harman, 2007 p.360). It is "an arrangement of resources and procedures used to promote learning". Over the years ADDIE has been continuously revised, however all the models consist of these five basic phases: Analysis,
Design, Development, Implementation, and Evaluation. To be effective, one phase should be completed to move to the next phase. Blanchard and Thacker (2006) summarize the ADDIE model as such:

1.Analysis: The first phase in the ADDIE model. In this phase organization's training needs are identified (known as Training Needs Analysis). As a result, performance gap is identified. Once a gap is identified, the cause of the gap must be determined. For example, the cause of the performance gap might be inadequate employee skills which can be solved by adequate training for this skill deficiency (Knowledge, Skills, and Abilities causes, known as KSA). Of course there could be other causes which could not be solved with training, and require alternative solutions (non-KSA causes).

2. Design: The training needs identified in the first stage are the inputs in this stage. Training objective is developed to specify the organizational and employee outcomes to be achieved.

3. Development: In this phase instructional strategy is formulated which includes developing manuals, identifying facilities and equipment needed. All these are integrated into a training plan to achieve the training objective. Yet most companies fail at this stage due to failure to identify analysis and design phases. There should be a pilot program to continuously evaluate and refine the training.

4. Implementation: In this stage the training is delivered to the training audience.

5. Evaluation: This is the final phase which ensures the training achieved its goals. There are two parts. Formative and Summative Evaluation. Formative evaluation assesses and revises the process of each stage, so that the objective of each stage is achieved. Summative evaluation assesses the end outcome of the training 
and the content and summarizes its' effects on the trainees, department and the organization. However many organizations fail at this stage due to inadequate measurements, surveys and assessments of the impact of the training.

Training plan can be arranged formally or informally. However, in this research our study will be only on formal training.

- Shayo et al., (1999), cited in Wu and Rocheleau (2001) define formal training as planned previously and organized according to a specific program and schedule. It usually undertakes personal and specific topics. Employees take these trainings on-the-job or off-the-job according to the content of the training and the type of skill or knowledge needed to acquire.

- Informal training on the other hand is a spontaneous and unstructured training due to a sudden need to a certain topic required to improve and develop skills, knowledge and abilities (Coombs 1985, cited in Wu and Rocheleau 2001).However, according to $\mathrm{Wu}$ and Rocheleau (2001), formal training may lead to informal training and vice versa, because each type of training may generate a new interest in a certain topic or a path to fulfill the training experience in a different approach.

This article attempts to investigate the perception of managers about their training process in a manufacturing company. We followed a qualitative methodology using an interview guide and we interviewed twelve managers.

\section{Methodology}

\section{Approach}

Post-Positivism approach will be used for this research. Post-Positivism also known as realism, thrives for objectivity (Menassa, 2014). The main objective is to interpret the policies and the practices used to train, develop and retain employees, and their implications on the employee's job satisfaction. We will study the point of view and experiences of the managers to have a good understanding of developing employees.

This research will follow a deductive reasoning approach, since it starts with a general theory that; training has certain influences on employee's job satisfaction. Deductive reasoning: Also called "top-down approach", starts with a general theory, narrowed down into specific hypotheses. It is narrowed down further with specific observations that are tested and eventually confirming the general theory.

\section{Population}

The population is the top management of a Lebanese manufacturing company. This company, as of September 2014, is compromised of 501 full time employees, divided into 29 various departments and processes. The bulk of the workforce is located at the plant which has around 501 full time employees, whereas the rest of the employees are located at the head office and the sales office.

For clarification, the workforce is divided into four sections; unskilled/semi-skilled labor, skilled/specialized labor, supervisory and top management. The unskilled/semiskilled labor section with 224 employees represents $45 \%$ of the workforce; it is composed of employees who have low level technical abilities, such as clericals, housekeepers, guards, technicians and drivers. The skilled/specialized labor section with 193 employees represent 38\% of the workforce, it is compromised of employees who poses specific and high technical abilities, such as group leaders, senior technicians, heavy machinery drivers and administrative employees. The supervisory section with 63 employees represents 13\% of the workforce, it is compromised of employees who have subordinates and are responsible for them includes foremen, 
assistant managers, and engineers. Finally, top management is composed of 22 employees who represents $4 \%$ of the workforce and have financial and managerial authority, such as managers and directors. For the purpose of this article, the sample is composed of 12 top managers out of the 22 managers and directors of the company.

\section{Instrumentation}

Personal interviews were conducted with the top management section that was responsible for the preparation and the operation of the training and development program. The interviewees are the following: HR manager, CFO, plant administrator, QHSE and site and civil manager, quarry manager, personnel manager, supply chain manager, electrical and instrumentation manager, cement mills and packing plant manager, Lab manager, accounting manager and MIS manager. Interviews will be semi-structured, recorded and an interview guide will set guidelines on what topics to cover and how to proceed. This will allow the interviewer to prepare competent questions ahead of time, and allow some means of deviation from the questions so that the interviewee will feel free to express his thoughts and views. These interviews covered 12 out of the 22 employees in top management section, which represents $54.5 \%$ of the workforce in that section.

\section{Analysis}

The data collected from the twelve interviews were thoroughly analyzed and as a result, various topics regarding training were identified. To simplify the explanation, we divided and summarized the topics into five sections with quotations from various interviewees accordingly. The following are the sections in which the qualitative data were divided:

1. Training policies, norms and methods implemented

2. Assessment of training and challenges
3. Benefits of training and employee participation

4. Career development and its' benefits

\section{Training Policies, Norms and Methods Implemented}

All of the respondents mentioned that they have training plans in their departments with the majority deriving their department's trainings from the performance appraisal's outcome and the yearly training needs analysis, where gaps are identified and developed. The training topics ranged from health, safety, environment, job development, technical and behavioral skills.

"We have a continuous training in the department; the training's are based from yearly performance appraisals and from departmental and personal programs." (I.1)

"It is done through two things. First trainings arising from the performance appraisal, second we have a continuous training such as brainstorming between me and my employees, it is like an informal training." (I.2)

"First of all we rely on the result of the yearly appraisal to detect the weaknesses in our employees, based on that we ask for training in order to fill the gap." (I.4)

Candidates for training are chosen according to the needs of the employees and the target level of the training.

"The candidates for the trainings are done based on employee's skills and job profile first of all and secondly based on the type of the training." (I.1)

"Who attends the training depends on the type of training and the situation." (I.3)

"According to the needs of the employees and also the target level of the training. If the training is intended for the level two employees (engineers, assistant managers) then you can't include a level three employee, 
because it will bring no added value to him and vice versa. " (I.10)

Both internal and external trainings are implemented in the majority of the departments.

Internal trainings are mainly used for safety, health and environment through the weekly/monthly departmental meetings. Also for specific technical trainings, because as cement manufacturing industry specific trainings aren't available in the market, as a result highly qualified and specialized employees transfer their skills to their fellow employees according to the needs.

"However if certain trainings are needed, and certain employees in the department are highly qualified, we do the trainings (internal training)." (I.4)

"This is a cement manufacturing industry it is very hard to find specific trainings. So, some specific trainings are done on the job, where potential employees are identified who can train different tasks each one in his specialty and according to their skills inventory." (I.6)

"Internal trainings are limited, they are mostly done for health, safety, environment and specific training's done by the QHSE department or a manager of a process." (I.10) On the other hand external trainings are used when there is a new machinery or process. Also in some instances employees are sent abroad for job development, especially since there are no trainings in cement in Lebanon. Moreover in some instances external trainers are brought to give in-house training especially if the number of trainees is high. Finally external training is used for general trainings which are aligned with the organization's strategy.

"There are some instances when an external instructor comes over to our company to do certain training. When a new polycom was installed, a representative from that firm trained the employees extensively for ten days." (I.5)

"External trainings are used for gaining new skills and improving quality, for example we sent employees abroad for workshops and sometimes if there is a group of trainees we prefer brining an external instructor in house." (I.6)

"External training's are those that are common in various departments, like the change of culture." (I.10)

Half of the respondents stated that employee's value external trainings more because they see it as more professional, however the other half indicated that if employee's really want to learn and acquire new skills, it shouldn't matter to them whether it's internal or external training.

"External training motivates employees more because they weight it more valuable and see it more professional." (I.7)

"Regarding whether if employees prefer internal or external trainings, for me if employee's really wants to learn and acquire a new skill, it shouldn't matter to them wither its internal or external training." (I.3)

"For me it doesn't matter if the training is by an internal or external instructor, what matters is the methodology of the training and on how you transfer the training material to the employees." (I.4)

\section{Assessment of Training and Challenges}

All clarified that after training is conducted they measure and assess how successful it was whether informally or formally. Some even evaluate trainings as they happen by requiring their employees to give them feedback regularly to check if everything is going well and they are benefiting.

"Yes off course, I always have a brief from the trainees after a training, I interview them on how it was and what did you learn." (I.1) 
"Usually the trainings are evaluated by the HR through training reports after the training is completed. However if there is an external training I regularly keep in touch with my employees to check if the quality of the training is good, if they are facing any problems with the material or the instructor, and if they do I contact the institution or the instructor." (I.7)

"After the training the employee's performance and behavior is monitored. If you do training and don't implement it, what is the point of that training?" (I.8)

There are two major problem faced by the concerned department managers when it comes to training. The first is the lack of trainings, courses and workshops related to industries in Lebanon whether by universities or training institutions. Second scheduling for certain training since it is quite difficult to find the right time that suits all the concerned employees in the training.

"Yes we have a problem because the trainings aren't always in Lebanon, and if they are done in Lebanon they are scheduled afternoon, the employees feel tired." (I.9)

"Sometimes it is hard to find the right trainings specifically when it comes to health, safety and specific technical trainings. This is because a cement manufacturing company, universities or institutions in Lebanon don't teach you for example how to operate a kiln. So we send employees abroad or in-house training through external instructors." (I.11)

"The major problem faced is allocating time for trainings. We have a training plan, but it is hard to dedicate time for it due to work overload and different shifts." (I.3)

\section{Benefits of Training and Employee Participation}

There were multiple benefits identified by the interviewees, differing from one department to another. Here are some of the mentioned benefits:
Improved employee performance and proficiency since they are more knowledgeable and skillful

Increased job engagement and loyalty which increases employee motivation and reduces absenteeism rate

Better productivity and competitiveness because of reduced cost of production such as less lost time and better maintenance.

Less accidents and lower accident severity rate due to employee's awareness, decrease employee mental and physical stress.

"The monthly health and safety monthly meetings decrease the accidents rate and severity." (I.6)

"The employees have less stress, because they have better maintenance on their machines due to improved technical skills and off course they will perform better." (I.3)

"Since employees are trained and they know more, so they will perform better." (I.2)

"Yes I agree because in my opinion giving training to the employee's is a motivating factor and engages employees. It is not like employees work all day and at the end of the month here is your salary." (I.6)

According to the mangers all the employees are motivated to participate in the trainings since they will acquire new skills. However the older employees are less motivated since they are not used to change and are indifferent since they think they have reached the maximum of their career path.

"Off course they are motivated. As I mentioned before trainings benefit them on different levels, it benefits them personally, gives them the chance to develop technically and it's a way of changing routine." (I.12)

"Higher level employees are more motivated to attend trainings, however lower level employees and older employees are less 
tending to be excited and motivated for employees, because they are not used to change and their mentality." (I.6)

\section{Career Development and its Benefits}

The vast majority of the respondents declared that even tough training has impact on creating some kind of employee loyalty and retention, however it is not enough. When you train employees, you have to offer them a career development plan, such as job enlargement and career path.

"It can contribute, but it is not the only factor. To increase loyalty, it needs trust and confidence. Of course it's a motivating factor when the company sends his employee's abroad for training, but it isn't the only factor that creates increased retention rate." (I.1)

"You have to create challenging projects because no ambitious employee stays in the same position with routine tasks." (I.9)

As mentioned by the CFO "career development is what your people are looking for". Here are the major benefits of career development seen by the interviewees:

Employees can survive any change and uncertainty since they are more knowledgeable

Employees are empowered. This creates commitment and motivation

Multiskilling decreases dependency and the need for more manpower

Improved department productivity due to multiskilling

"Simply if a career development plan exists, employees will feel committed and enthusiastic, since he knows his effort will be rewarded." (I.2)

"Multiskilling decreases the number of jobs needed, more productivity and efficiency that are you will have time to do more activities and improvement in quality." (I.3)
"Thanks to the technical trainings the employees can survive any change." (I.4)

"The benefits for career development in this department include lifting up the knowledge of the employees, hence lifting up the quality and productivity of the department." (I.7)

Fourteen out of the sixteen departments represented in the interview enforce multiskilling. Employees are developed to be able to do all the tasks of the department and to be aware of all the functions of the department.

"All the employees in the QHSE department are multiskilled and can be co-assigned to other tasks and position within the department." (I.7)

"The goal is to create rotation between employees and each position, every week they drive a different machine. Around 90\% of my employees are multiskilled." (I.8)

"Yes there is multiskilling and specialty, however multiskilling is encouraged and it is done by internal trainings. Sometimes some departments work together on an assignment as if they are merged, in order to have some knowledge of how work is done in other departments." (I.6)

All the managers concluded that an ongoing constructive communication with their employees regarding their career path is very vital, since you will be outlining the employee's future and they will not be in a dark tunnel. Also all noted that performance appraisal is very crucial in outlining the employee's weaknesses and identifying the gaps needed to develop.

"There should be a daily ongoing communication between them, when a person in the department has a say or has a need he shouldn't back off, and also when the manager sees that his employee is underperforming and can improve he shouldn't hesitate and wait for the performance appraisal." (I.12) 
"During the performance appraisal we talk about the career path of the employee, where you see him in a few years and where he can be. We give him the idea, we enlarge his responsibility and decision making." (I.9)

Inter-departmental communication is mostly done on managerial level and based on need. All of the managers agreed that they need to develop their communication and be proactive.

"There is some communication between departments but not often." (I.11)

"Yes we do communicate with other departments, but it needs to be developed." (I.12)

"There is a communication, but on managerial level only." (I.4)

\section{Conclusion}

This study has provided us with the support that investing in training is a wise initiative with added value and not just an additional expense that organizations have to incur. We understand that the training and development plans which are being implemented regularly, not only widen their employee's knowledge, abilities and skills, but provide various opportunities, such as: increase in employee job satisfaction, improvement in performance and motivation through multiskilling and commitment to the job and the organization. All these come consistent with the theories mentioned in the literature review section on training and development, and the qualitative researches done

\section{References}

1. Beardwell, I. and Holden, L. (2001) Human Resource Management. A Contemporary Approach. Essex: Pearson Education Limited.
2. Blanchard, P.N. and Thacker, J.W. (2006) Effective Training: Systems, Strategies and Practices. 3rd ed. Prentice Hall.

3. Coget, J. (2011) 'Does National Culture Affect Firm Investing in Training and Development?' Academy of Management Perspectives, 25(4): 85-87.

4. Cole, G. A (2002) Personnel and Human Resource Management. 5th ed. York Publishers, Continuum London, UK.

5. Coombs, P.H. (1985) The World Crisis in Education: A View from the Eighties. New York: Oxford University Press.

6. Dirani, K. (2006) 'Exploring Socio-Cultural Factors that Influence HRD Practices in Lebanon'. Human Resource Development International, 9(1): 85-98.

7. Gagne, R. M. Wager, W.W. Golas, K.C. and Keller, J.M. (2005) Principles of Instructional Design. 4th ed. Belmont, CA: Wadsworth/Thompson Learning.

8. Jolles, L. (2005). How to Run Seminars and Workshops. 3rd ed. New Jersey: John Wiley and Sons.

9. Koohang, A. and Harman, K. (2007) Learning Objects and Instructional Design. Santa Rosa, California: Informing Science.

10.Menassa, E. (2014) Business Research Methodology, BUS668. [Lecture 4] Strategic Philosophical Debates. Notre Dame University.

11.Milhem,W. Abushamsieh, K. Aróstegui, M. N. P. (2014) 'Training Strategies, Theories and Types'. Journal of Accounting - Business \& Management, 21(1): 12-26.

12.Nassazi, A. (2013) Effects of Training on Employee Performance: Evidence from Uganda. MBA thesis, Vaasan Ammattikorkeakoulo. University of Applied Sciences. 
13. Robert, R. and Shamsuddin, A. (2000) 'The Relationship Between Workplace Learning and Job Satisfaction in Small to Mid-sized Businesses in Malaysia'. Human Resource Development International, 3(3): 307-322.

14.Shayo, C. Olfman, L. and Teitelroit, R. (1999) 'An Exploratory Study of the Value of Pretraining End-User Participation'. Information Systems Journal, 9: 55-79.
15.Sultana, A. (2012) 'Impact of Training on Employee Performance: A Study of Telecommunication Sector in Pakistan'. Interdisciplinary Journal of Contemporary Research in Business, 4(6): 646-661.

16.Wu, L. and Rocheleau, B. (2001) 'Formal Versus Informal End User Training in Public and Private Sector Organizations'. Public Performance and Management Review, 24(4): 312-321. 